\title{
HSP70 overexpression may play a protective role in the mouse embryos stimulated by CUMS
}

Xiao-Hong Li', Hou-Qing Pang ${ }^{2}$, Lang Qin', Song Jin ${ }^{1}$, Xun Zeng ${ }^{1}$, Yu Bai ${ }^{1}$ and Shang-Wei Li ${ }^{1 *}$

\begin{abstract}
Background: We evaluated whether heat shock protein HSP70 plays a protective role in the embryos of Kunming mice subjected to chronic unpredictable mild stress.

Methods: Female mice were stimulated for 4 weeks with nine stressors and then divided into mild, moderate and severe stress groups. Superovulation was induced with a gonadotropin preparation (PMSG/HCG) and HSP70 expression in 2-cell embryos and day 4 embryos was detected by immunofluorescence (IF) and real-time polymerase chain reaction (RT-PCR).

Results: In the mild stress group, ovarian response and oocyte development potential were similar to those of the control group, while the HSP70 mRNA levels of the embryos were significantly higher $(P<0.05)$. In the severe stress group, ovarian response and oocyte development potential decreased compared with the control group $(P<0.05)$, while the HSP70 mRNA levels were similar. The results of the moderate stress group were intermediate among the three groups. Furthermore, HSP70 mRNA levels of the embryos were shown to be positively associated with parameters of oocyte and embryo development potential $(P<0.05)$.
\end{abstract}

Conclusions: HSP70 overexpression may play a protective role in the embryos of the mild or moderate stress mice stimulated by chronic unpredictable mild stress.

Keywords: Heat shock protein70, Chronic unpredictable mild stress, Embryos, Immunofluorescence, Real-time polymerase chain reaction

\section{Background}

Stress is a complex state of threatened homeostasis, which mobilizes a composite spectrum of nervous, endocrine, and immune system responses to restore and maintain homeostasis. In the neuroendocrine network, the reproductive endocrine system is not only involved in the response to stress, but is more vulnerable to stress damage than other systems. Studies have confirmed that stress can affect the human menstrual cycle, leading to primary dysmenorrhea, premenstrual syndrome and hypothalamic amenorrhea [1-3]. Chronic psychosocial stressors are detrimental to the ovarian reserve of infertile women [4-7], and stressful life events are associated

\footnotetext{
*Correspondence: lishangweilxh_001@163.com

${ }^{1}$ Reproductive Medicine Center, West China Second Hospital of Sichuan University, Chengdu, Sichuan, China

Full list of author information is available at the end of the article
}

with poor in vitro fertilization outcomes [8-10]. Both infertility and its treatment using assisted reproductive technology (ART) are stressful. Couples often describe the experience of infertility as a critical, significant life event associated with emotional challenges [11-13]. Some infertile patients undergoing ART have reported high levels of depressive symptoms, anxiety and distress [14-18]. A meta-analysis found that stress, trait anxiety and state anxiety had negative associations with clinical pregnancy rates for patients undergoing ART [8].

Although animal models cannot replicate human psychopathology in every detail, they offer the possibility of evaluating the main effects and interactions in a controlled, prospective manner. Chronic unpredictable mild stress (CUMS) is one of the behavioral models used to simulate human depression in some respects, such as loss of normal aggressiveness [19]. This animal model is 
consistent with ethical principles for scientific experiments on animals and has validity [20]. Our research group established the CUMS animal model with Kunming mice for the first time. We found that after the administration of pregnant mares' serum gonadotropin (PMSG) and human chorionic gonadotropin (hCG) to induce superovulation, the numbers of oocytes and embryos obtained from the mice decreased under CUMS conditions. Wu et al. [21, 22] also reported that CUMS inhibited follicular development and increased follicular atresia.

There are clinical cases reporting successful pregnancies in women in a stressed state [18], so we inferred that their reproductive biology might be protected against stress factors. Heat shock proteins (HSPs) are highly conserved cellular stress proteins present in every organism from bacteria to humans. They were first described in 1962 as leading to a puffing pattern on Drosophila polytene chromosomes after thermal stress [23]. As a member of the HSP superfamily, HSP70 may act as a molecular chaperone, and assist in the cell stress response by resisting apoptosis and oxidative stress, and regulating immune responses [24]. Apart from expression in tumors and sensitive organs such as the brain and heart, HSP70 is also expressed in the ovaries, endometrium, decidua, placenta and amniotic fluid, and it may play a role in oogenesis and embryogenesis. The body may protect its reproductive function by increasing the expression of HSP70 when subjected to thermal and oxidative stressors [25]. However, no studies have yet investigated the levels of HSP70 in the female reproductive system under psychological stress.

This study aimed to explore the expression of HSP70 in the response of embryos in a Kunming mouse model of CUMS following ovarian superovulation.

\section{Methods \\ Animals}

This study was carried out in strict accordance with the recommendations in the Guide for the Care and Use of Laboratory Animals of the National Institutes of Health. The protocol was approved by the Committee on the Ethics of Animal Experiments of Sichuan University (Permit Number: AE2014034). All surgery was performed under sodium pentobarbital anesthesia, and all efforts were made to minimize suffering. Female Kunming mice (4-5 weeks old) were obtained from the Animal Service Center of Sichuan University and were assigned by random number table to two groups: an unhandled control group and the experimental CUMS group. Mice were housed five per cage and were acclimatized to the animal colony for one week under the following conditions: standard rodent diet and tap water ad libitum, a 12/12 h light/dark cycle (lights on 07:30-19:30 h), and a constant temperature of $21-22{ }^{\circ} \mathrm{C}$ and humidity of $55-65 \%$. The experimental group then underwent a 4-week CUMS procedure, while the control group continued with the same conditions used during acclimatization.

\section{Stress induction}

There were 150 mice in the experimental group and 50 in the control group. The CUMS protocol was adapted from our former method and revised [26]. The experimental mice were stimulated for 4 weeks with one of the nine stressors in the same order each day. The nine stressors were as follows: (1) 24-h damp bedding and cage tilting (cages were tilted to $45^{\circ}$ from the horizontal); (2) 4-h restraint; (3) 5-min swimming in an ice bath; (4) 24-h food deprivation; (5) 24-h water deprivation with empty drinking bottles; (6) 24-h social isolation (one mouse per cage); (7) 5-min heat stress in an oven at $40{ }^{\circ} \mathrm{C}$; (8) 1-min tail clamping; (9) 24-h exposure to strange objects such as plastic cups, spoons, or pieces of cloth. Each stressor was carried out in each experimental mouse 3 or 4 times in the 4-week CUMS.

\section{Open field test (OFT) and sucrose consumption}

After 4 weeks of CUMS, we applied an OFT and a sucrose consumption test to the experimental and control mice. For the OFT, we constructed a box measuring $60 \times 60 \times 40 \mathrm{~cm}$ with matte white acrylic, placed a mouse inside and measured the time spent in the center, any distance moved (number of cross lattices), rearing (vertical) activity, grooming time, and defecation (number of fecal boli) over $5 \mathrm{~min}$ [27]. In the sucrose consumption test, we calculated each mouse's consumption of $2 \%$ sucrose in $4 \mathrm{~h}$. We also measured the body weight of the experimental and control mice before and after the 4week CUMS.

\section{Division of experimental group}

According to the data of the OFT and the sucrose consumption test, we found that the time spent in center, the distance moved, rearing count and defecation of the OFT and the sucrose consumption were different between the experimental group and the control group. Apart from the narrow range of the defecation and sucrose consumption, we chosen three indicators of the OFT including the time spent in center, distance moved, rearing count to divide stress levels of experimental mice. The cut off values of the time spent in center in mild, moderate and severe stress groups were $8 \mathrm{~s}$ and $11 \mathrm{~s}$, respectively. The cut off values of distance moved in mild, moderate and severe stress groups were 75 and 90 cross lattices, respectively. The cut off values of rearing count in mild, moderate and severe stress groups were 14 and 11 times, respectively. 
So, we defined the mild stress mice as: time spent in the center was 6-8 s, or the distance moved was 90-105 cross lattices, or the rearing count was 14-16 times. Moderate stress mice were defined as: time spent in the center was 9-11 s, or the distance moved was 75-89 cross lattices, or the rearing count was 11-13 times. Severe stress mice were defined as: time spent in the center was 12-14 s, or the distance moved was 60-74 cross lattices, or the rearing count was 8-10 times. These mice were also defined as severe stress ones if they had at least one indicator that is in line with the severe standards, and so on.

\section{Collection of mouse embryos}

The mice were injected intraperitoneally with $10 \mathrm{IU}$ PMSG (Animal Center of Tianjin, P. R. China) at $4 \mathrm{pm}$, followed by an injection of 10 IU of hCG (Biochemical Pharmaceutical Factory of Shanghai, P. R. China) 46$48 \mathrm{~h}$ later. After the second injection, females were placed two per cage with fertile male mice. The day of sighting a vaginal plug was designated as day 1 (D1) post coitum (pc). Mated females were separated from males on D1 pc. Their 2-cell embryos were obtained at $2 \mathrm{pm}$ D2, and their morula-early blastocysts were obtained on $\mathrm{D} 4$.

High-quality embryos on D4 were defined as those classifiable as grade I-III according to the published criteria for human embryos [28].

\section{Real time polymerase chain reaction (RT-PCR)}

RNA was extracted from 50 2-cell embryos or 30 D4 embryos collected from the mice in vivo, using RNeasy Micro Kits (Qiagen Inc., Germany) according to the manufacturer's instructions. $\beta$-actin was a housekeeping gene for normalization of this data. The RT-PCR reactions were performed in a final volume of $20 \mu \mathrm{L}$, containing $10 \mu \mathrm{L}$ of SYBR Green master mix (Roche Diagnostics, Indianapolis, IN, USA), $3 \mu \mathrm{L}$ of $\mathrm{H}_{2} \mathrm{O}, 1 \mu \mathrm{L}$ each of forward primer (GAGGAGTTCAAGAGGAAG) and reverse primer (TGATGGATGTGTAGAAGTC) and $3 \mu \mathrm{L}$ of cDNA template or water (non-template negative control). An ABI 7500 thermal cycler (Applied Biosystems, Foster City, CA, USA) was employed for RT-PCR amplification, which was performed under the following conditions: one cycle of $95{ }^{\circ} \mathrm{C}$ for $10 \mathrm{~min} ; 45$ cycles of $95{ }^{\circ} \mathrm{C}$ for $15 \mathrm{~s}, 56^{\circ} \mathrm{C}$ for $30 \mathrm{~s}, 72{ }^{\circ} \mathrm{C}$ for $30 \mathrm{~s}$; and a final cycle of $95{ }^{\circ} \mathrm{C}$ for $15 \mathrm{~s}, 60{ }^{\circ} \mathrm{C}$ for $15 \mathrm{~s}$, and then a gradual increase to $95{ }^{\circ} \mathrm{C}$ over $30 \mathrm{~min}$ at a ramp rate of $2 \%$ for melting curve analysis.

\section{Immunofluorescence (IF) staining}

For IF localization of HSP70, 2-cell and D4 embryos were fixed in freshly prepared $4 \%$ paraformaldehyde (Sigma-Aldrich, St Louis, MO, USA) in phosphate- buffered saline (PBS) for $1 \mathrm{~h}$ at room temperature (RT), washed in PBS supplemented with $2 \%(\mathrm{w} / \mathrm{v})$ bovine serum albumin (Sigma-Aldrich; PBS-BSA) by pipetting through three sequential $50 \mu \mathrm{L}$ drops, which were then transferred to $0.1 \mathrm{M}$ glycine (Sigma-Aldrich) in PBSBSA for $5 \mathrm{~min}$ at RT to neutralize aldehydes. After washing again in PBS-BSA (as above) embryos were permeabilized in $0.1 \%$ Triton X-100 in PBS for $10 \mathrm{~min}$ at RT, then washed a third time in PBS-BSA. The embryos were incubated overnight at $4{ }^{\circ} \mathrm{C}$ with a $1: 100$ dilution of mouse monoclonal anti-HSP70 antibody (ab5439; Abcam). Negative controls were treated with PBS-BSA alone. Embryos were then washed and incubated with a 1:100 dilution of goat anti-mouse IgG (Beijing Zhongshan Jinqiao Biotechnology Co., Ltd., Beijing, P. R. China). Embryos were washed and counterstained with Hoechst $33258(0.5 \mu \mathrm{g} / \mathrm{mL}$; Santa Cruz Biochemical Co., Santa Cruz CA, USA) to stain the cell nuclei.

\section{Statistical analyses}

Measurements are shown as the mean \pm standard deviation (SD) and analyzed by Student's $t$ test, ANOVA and the LSD test. Numeric data such as the rates of fertilization and development of high quality embryos were evaluated with the $\chi^{2}$ test and the partitioning $X^{2}$ method. Correlations were analyzed using linear correlation. All statistical analyses were performed using SPSS version 17.0 (IBM Corp., Armonk, NY, USA) and significance was defined as $P<0.05$.

\section{Results}

Validation of the mouse CUMS model by OFT and sucrose consumption test

After 4 weeks of CUMS, the body weight of the experimental mice was $29.5 \pm 4.7 \mathrm{~g}$, which was significantly lower than the control group $(33.9 \pm 5.1)(P<0.05)$.

Data obtained on the time spent in the center of the box, distance moved, rearing, grooming and defecation activities in an open field are shown in Table 1. Compared with the control group, the time spent in the center and amount of defecation in stressed mice increased significantly $(P<0.05)$, while the distance moved and amount of rearing decreased significantly in the stressed mice $(P<0.05)$. After 4 weeks of CUMS, the sucrose consumption of the stressed mice was significantly less than in the control group $(P<0.05$; Table 1$)$.

According to the results of the time spent in the center, distance moved and rearing activities, we divided the experimental mice into mild, moderate and severe stress groups. Among the 150 experimental mice, there were 75 mild stress mice $(50 \%), 55$ moderate stress mice (37\%), and 20 severe stress mice (13\%). 
Table 1 Open field test and sucrose consumption test results after 4 weeks of chronic unpredictable mild stress (CUMS)

\begin{tabular}{llll}
\hline & Control group & Stressed group & $P$ value \\
\hline No. of mice & 50 & 150 & \\
Body weight (g) & $33.9 \pm 5.1$ & $29.5 \pm 4.7$ & $<0.05$ \\
Time spent in center (s) & $4 \pm 1$ & $10 \pm 4$ & $<0.05$ \\
$\begin{array}{l}\text { Distance moved } \\
\text { (no. of cross lattices) }\end{array}$ & $166 \pm 38$ & $81 \pm 21$ & $<0.05$ \\
Rearing count & $39 \pm 9$ & $12 \pm 4$ & $<0.05$ \\
Grooming count & $3 \pm 1$ & $4 \pm 1$ & NS \\
Defecation (no. of fecal boli) & $2 \pm 1$ & $4 \pm 2$ & $<0.05$ \\
Sucrose consumption (g) & $4 \pm 1$ & $2 \pm 1$ & $<0.05$ \\
\hline
\end{tabular}

Data are shown as the mean \pm SD and were analyzed using Student's $t$ tests. NS not significant

\section{CUMS decreased the ovarian response to superovulation}

Table 2 shows the influence of CUMS on the development potential of oocytes and embryos after ovarian hyperstimulation. The numbers of retrieved oocytes, 2-cell embryos, D4 embryos including high quality embryos and blastocysts, fertilization rate, and high quality embryo rate at D4 among the moderate and severe stress groups compared with the control group were significantly different $(P<0.05$, Table 2$)$, while the mild group was not significantly different to the control group. Further statistical analysis showed that compared with the control group, these variables were all significantly lower in the moderate or severe stress groups.

Expression of HSP70 in 2-cell and D4 embryos after CUMS The IF results showed that HSP70 was distributed mainly in the embryo cytoplasm or around the zona pellucida of the stressed mice (Fig. 1). HSP70 was expressed in $87 \%$ of the 2 -cell embryos and $83 \%$ of the D4 embryos of mild stress mice, while for the moderate stress mice these values were 60 and $47 \%$, respectively; these values were significantly higher than for the control group $(P<0.05$, Table 3$)$. However, no differences were observed for the 2-cell and D4 embryos of the severe stress group compared with the control group. RT-PCR results similarly showed that compared with the control group, the HSP70 mRNA levels in the 2-cell and D4 embryos of the mild and moderate stress mice were significantly higher, while no differences were observed for the severe stress mice (Table 3).

\section{The association between expression of HSP70 in embryos and other variables following CUMS}

Statistical analysis showed that the HSP70 mRNA level in the D4 embryos was positively associated with the number of retrieved oocytes, 2-cell embryos, and D4 embryos; the fertilization rate and high quality embryo rate; and the HSP70 mRNA level of the 2-cell embryos $(P<0.05$, Table 4$)$. We did not find any correlation between the HSP70 mRNA level of the D4 embryos and the blastocyst formation rate, and the body weight of mice.

\section{Discussion}

In this study, we applied one of the nine stress factors (see stress induction) each day for 4 weeks to develop an effective CUMS female animal model. Under conditions of CUMS, mice showed depressed behavior, similar to the human reaction to chronic and low-intensity adverse events in daily life. Unlike CUMS, chronic restrain stress can't induce depression-like behaviours but anxiety-like behaviours in mice [29]. The OFT and sucrose consumption test were used to evaluate the validation of the CUMS animal model. The OFT was used to assess locomotor activity and exploratory behavior and the sucrose consumption test was applied to detect anhedonia. According to the data of the time spent in the center of the box, the distance moved, and the rearing count of the OFT, we divided the experimental mice into mild, moderate and severe stress groups for further

Table 2 Development potential of oocytes and embryos after 4 weeks of CUMS

\begin{tabular}{|c|c|c|c|c|c|}
\hline & Control group & Mild stress group & Moderate stress group & Severe stress group & $P$ value \\
\hline No. of mice & 20 & 20 & 20 & 20 & \\
\hline No. of oocytes ${ }^{a}$ & $32 \pm 7$ & $29 \pm 5$ & $22 \pm 6^{*}$ & $15 \pm 5^{*}$ & $<0.05$ \\
\hline Fertilization rate ${ }^{\mathrm{b}}$ & $87 \%$ & $78 \%$ & $61 \% *$ & $40 \% *$ & $<0.05$ \\
\hline No. of 2-cell embryos ${ }^{a}$ & $27 \pm 5$ & $22 \pm 4$ & $15 \pm 5^{*}$ & $9 \pm 2^{*}$ & $<0.05$ \\
\hline No. of D4 embryos ${ }^{a}$ & $24 \pm 4$ & $18 \pm 3$ & $10 \pm 4^{*}$ & $4 \pm 2^{*}$ & $<0.05$ \\
\hline No. of high quality embryos ${ }^{a}$ & $20 \pm 5$ & $13 \pm 4$ & $5 \pm 2^{*}$ & $1 \pm 1^{*}$ & $<0.05$ \\
\hline High quality embryo rate ${ }^{b}$ & $83 \%$ & $72 \%$ & $50 \% *$ & $25 \% *$ & $<0.05$ \\
\hline No. of blastocysts ${ }^{a}$ & $8 \pm 3$ & $5 \pm 2$ & $2 \pm 1^{*}$ & $1 \pm 1^{*}$ & $<0.05$ \\
\hline Blastocyst information rate ${ }^{b}$ & $33 \%$ & $28 \%$ & $20 \%$ & $25 \%$ & NS \\
\hline
\end{tabular}

${ }^{\mathrm{a}}$ Data are shown as the mean \pm SD and were analyzed by ANOVA and LSD testing

${ }^{b}$ Data are shown as rates and were analyzed by $X^{2}$ test and the partitioning $X^{2}$ method

${ }^{*} P<0.05$ compared with the control group, measured by LSD test or the partitioning $X^{2}$ method. NS not significant 

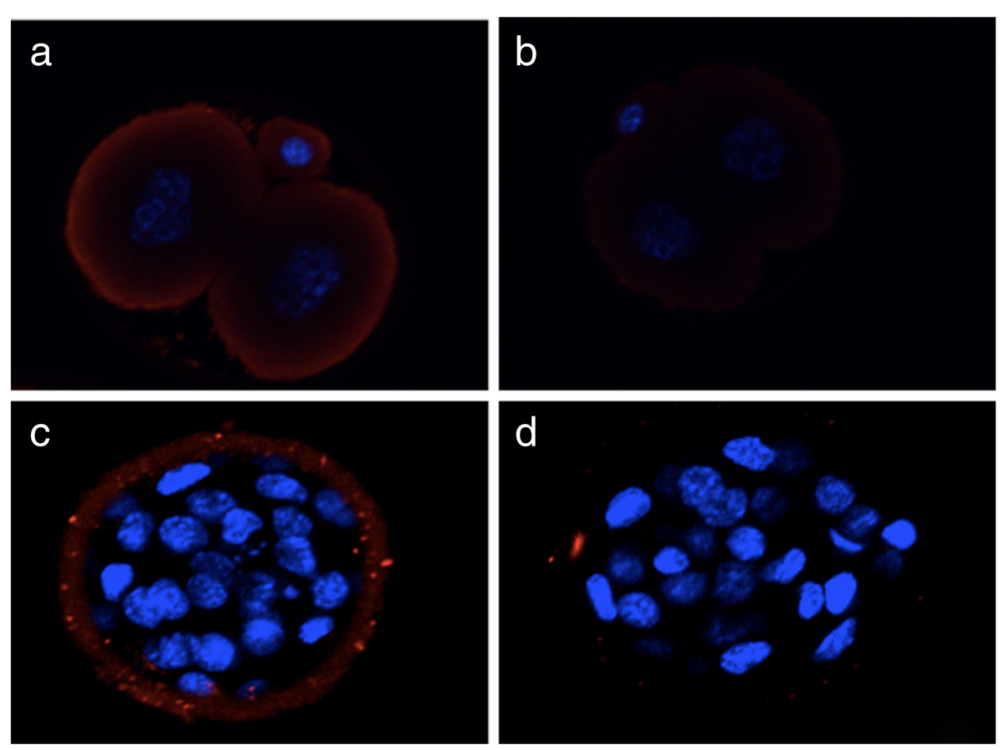

Fig. 1 Expression of HSP70 in 2-cell embryos and D4 embryos demonstrated by immunofluorescent staining. a 2-cell embryo from a stressed mouse. b 2-cell embryo of a control mouse. c D4 embryo from a stressed mouse. d D4 embryo of a control mouse. The expression of HSP70 was positive in the embryos from stressed mice, but negative in the control embryos

statistical analysis, which haven't been reported in other studies yet.

After administration of PMSG/hCG to induce superovulation, we found that moderate or severe stress mice stimulated by CUMS had a decreased ovarian response and oocyte development potential. Tetsushi HIRANO et al. also reported a reproductive suppression male mice model induced by CUMS [30]. This negative outcome resulted from multilevel interactions among the hypothalamicpituitary- adrenal axis and the hypothalamic-pituitarygonadal axis, the immune system, and the autonomic nervous system. Elizabeth et al. reported that stress

Table 3 Expression of HSP70 in 2-cell and day 4 embryos as measured by immunofluorescence and RT-PCR

\begin{tabular}{|c|c|c|c|c|c|}
\hline & $\begin{array}{l}\text { Control } \\
\text { group }\end{array}$ & $\begin{array}{l}\text { Mild stress } \\
\text { group }\end{array}$ & $\begin{array}{l}\text { Moderate } \\
\text { stress } \\
\text { group }\end{array}$ & $\begin{array}{l}\text { Severe } \\
\text { stress } \\
\text { group }\end{array}$ & $P$ value \\
\hline \multicolumn{6}{|l|}{$\mathrm{F}^{\mathrm{a}}$} \\
\hline $\begin{array}{l}\text { Positive 2-cell } \\
\text { embryos }\end{array}$ & $\begin{array}{l}10 \% \\
(3 / 30)\end{array}$ & $\begin{array}{l}87 \% \\
(26 / 30)\end{array}$ & $\begin{array}{l}60 \% \\
(18 / 30)\end{array}$ & $\begin{array}{l}13 \% \\
(4 / 30)\end{array}$ & $<0.05$ \\
\hline $\begin{array}{l}\text { Positive D4 } \\
\text { embryos }\end{array}$ & $\begin{array}{l}20 \% \\
(6 / 20)\end{array}$ & $\begin{array}{l}83 \% \\
(25 / 30)\end{array}$ & $\begin{array}{l}47 \% \\
(14 / 30)\end{array}$ & $\begin{array}{l}17 \% \\
(5 / 30)\end{array}$ & $<0.05$ \\
\hline \multicolumn{6}{|l|}{$R T-P C R^{b}$} \\
\hline $\begin{array}{l}\text { HSP70 of 2-cell } \\
\text { embryos }\end{array}$ & 1 & $6 \pm 2^{*}$ & $3 \pm 1^{*}$ & $1.2 \pm 1$ & $<0.05$ \\
\hline $\begin{array}{l}\text { HSP70 of D4 } \\
\text { embryos }\end{array}$ & 1 & $13 \pm 5^{*}$ & $7 \pm 3^{*}$ & $1.5 \pm 1$ & $<0.05$ \\
\hline \multicolumn{6}{|c|}{$\begin{array}{l}\text { Data are shown as rates and were analyzed by } x^{2} \text { test and the partitio } \\
x^{2} \text { method } \\
\text { b Data are shown as the mean } \pm \text { SD and were analyzed by ANOVA and } \\
\text { LSD testing } \\
{ }^{*} P<0.05 \text { compared with the control group, measured by LSD test }\end{array}$} \\
\hline
\end{tabular}

induced increased expression levels of receptors for glucocorticoids, which may cause an increase in gonadotropin inhibitory hormone production, contributing to the hypothalamic suppression of reproductive function [31]. Additionally, chronic unpredictable stress was shown to inhibit the production of intraovarian regulatory factors such as growth and differentiation factor 9 and brainderived neurotropic factor in follicles [21, 22].

HSC70 expression is known to begin with the onset of zygotic genome activity. It is the predominant HSP70 from the early 2 -cell embryo stage to the blastocyst stage. The induction of HSP synthesis by osmotic shock and heat shock begins in 1- or 2-cell embryos and the blastocyst stage, respectively [24, 32]. In our study, we

Table 4 Association between expression of HSP70 in embryos and other variables following CUMS

\begin{tabular}{lll}
\hline & $r$ & $P$ value \\
\hline No. of oocytes & 0.276 & $<0.05$ \\
Fertilization rate & 0.492 & $<0.05$ \\
No. of 2-cell embryos & 0.325 & $<0.05$ \\
HSP70 mRNA of 2-cell embryos & 0.576 & $<0.05$ \\
No. of D4 embryos & 0.355 & $<0.05$ \\
No. of high quality embryos & 0.423 & $<0.05$ \\
High quality embryo rate & 0.537 & $<0.05$ \\
No. of blastocysts & 0.413 & $<0.05$ \\
Blastocyst formation rate & 0.277 & NS \\
Body weight of mice & 0.252 & NS \\
\hline
\end{tabular}

Data were analyzed using linear correlation 
found that the mild stress mice stimulated by CUMS had a similar ovarian response and oocyte development potential compared with the control group. Our IF and RT-PCR showed that HSP70 induced by CUMS in 2-cell and D4 embryos of the mild stress mice were significantly higher than in the control group. Because HSP70 is a stress protective protein, we inferred that the unaffected reproductive function of the mild stress mice might be protected by the overexpression of HSP70. But the mechanism is not clear. Our further study will explore whether HSP70 plays its protective role in embryos according to interact with carboxyl terminal interacting protein (CHIP) [33], and whether cortisol response happens in this condition. On the other hand, in the severe stress group, the ovarian response and oocyte development potential decreased, and the HSP70 mRNA was also low. Severe stress might inhibit proper stress response to generate HSP70 to protect reproduction function, but the correlations with the nervous-endocrineimmune systems are also not clear, which should be studied further.

\section{Conclusions}

HSP70 overexpression may play a protective role in the embryos of mild or moderately stressed mice stimulated by CUMS. But in the severe stress condition, HSP70 level may not be sufficient to exert this protective effect.

\section{Competing interests}

The authors declare that they have no competing interests.

\section{Authors' contributions}

$\mathrm{XH}$ and $\mathrm{HQ}$ are co-first authors on this work; they participated in the design of the study, carried out the molecular biology studies and drafted the manuscript. QL carried out the immunoassays. JS performed the statistical analysis. ZX and BY participated in the animal experiments. SW conceived of the study, and participated in its design and coordination and helped to draft the manuscript. All authors read and approved the final manuscript.

\section{Acknowledgments}

We thank Prof. Li-Min Yue from the Department of Physiology, Academy of Basic and Forensic Medicine, Sichuan University, for her assistance with immunofluorescence staining.

\section{Author details}

${ }^{1}$ Reproductive Medicine Center, West China Second Hospital of Sichuan University, Chengdu, Sichuan, China. ${ }^{2}$ Department of Ultrasonography, West China Second Hospital of Sichuan University, Chengdu, Sichuan, China.

Received: 15 September 2015 Accepted: 11 November 2015 Published online: 16 November 2015

\section{References}

1. Bianco V, Cestari AM, Casati D, Cipriani S, Radici G, Valente I. Premenstrual syndrome and beyond: lifestyle, nutrition, and personal facts. Minerva Ginecol. 2014;66(4):365-75.

2. Sznajder KK, Harlow SD, Burgard SA, Wang Y, Han C, Liu J. Gynecologic pain related to occupational stress among female factory workers in Tianjin. China Int J Occup Environ Health. 2014;20(1):33-45.

3. Kordi M, Mohamadirizi S, Shakeri MT. The relationship between occupational stress and dysmenorrhea in midwives employed at public and private hospitals and health care centers in Iran (Mashhad) in the years 2010 and 2011. Iran J Nurs Midwifery Res. 2013;18(4):316-22.
4. Ebbesen SM, Zachariae R, Mehlsen MY, Thomsen D, Højgaard A, Ottosen L, et al. Stressful life events are associated with a poor in-vitro fertilization (IVF) outcome: a prospective study. Hum Reprod. 2009;24(9):2173-82.

5. Bleil ME, Adler NE, Pasch LA, Sternfeld B, Gregorich SE, Rosen MP, et al. Psychological stress and reproductive aging among pre-menopausal women. Hum Reprod. 2012;27(9):2720-8.

6. Bleil ME, Adler NE, Pasch LA, Sternfeld B, Gregorich SE, Rosen MP, et al. Depressive symptomatology, psychological stress, and ovarian reserve: a role for psychological factors in ovarian aging? Menopause. 2012;19(11):1176-85.

7. Cizmeli C, Lobel M, Franasiak J, Pastore LM. Levels and associations among self-esteem, fertility distress, coping, and reaction to potentially being a genetic carrier in women with diminished ovarian reserve. Fertil Steril. 2013;99(7):2037-44. e3.

8. Matthiesen SM, Frederiksen $Y$, Ingerslev HJ, Zachariae R. Stress, distress and outcome of assisted reproductive technology (ART): a meta-analysis. Hum Reprod. 2011;26(10):2763-76.

9. Quant HS, Zapantis A, Nihsen M, Bevilacqua K, Jindal S, Pal L. Reproductive implications of psychological distress for couples undergoing IVF. J Assist Reprod Genet. 2013;30(11):1451-8.

10. An Y, Sun Z, Li L, Zhang Y, Ji H. Relationship between psychological stress and reproductive outcome in women undergoing in vitro fertilization treatment: psychological and neurohormonal assessment. J Assist Reprod Genet. 2013;30(1):35-41.

11. Menning BE. The emotional needs of infertile couples. Fertil Steril. 1980;34:313-9.

12. Freeman EW, Boxer AS, Rickels K, Tureck R, Mastroianni Jr L. Psychological evaluation and support in a program of in vitro fertilization and embryo transfer. Fertil Steril. 1985;43:48-53.

13. Dunkel-Schetter C, Lobel M. Psychological reactions to infertility. In: Stanton AL, Dunkel-Schetter C, editors. Infertility: perspectives from stress and coping research. London, New York: Plenum Press; 1991. p. 29-57.

14. Greil AL. Infertility and psychological distress: a critical review of the literature. Soc Sci Med. 1997;45:1679-704.

15. Brkovich AM, Fisher WA. Psychological distress and infertility: forty years of research. J Psychosom Obstet Gynaecol. 1998;19:218-28.

16. Eugster A, Vingerhoets AJ. Psychological aspects of in vitro fertilization: a review. Soc Sci Med. 1999;48:575-89.

17. Chen TH, Chang SP, Tsai CF, Juang KD. Prevalence of depressive and anxiety disorders in assisted reproductive technique clinic. Hum Reprod. 2004;17:2313-8.

18. Li XH, Ma YG, Geng LH, Qin L, Hu H, Li SW. Baseline psychological stress and ovarian norepinephrine levels negatively affect the outcome of in vitro fertilization. Gynecol Endocrinol. 2011;27(3):139-43.

19. Ossowska G, Danilczuk Z, Klenk-Majewska B, Czajkowski L, Zebrowska- Lupina I. Antidepressants in chronic unpredictablemild stress (CUMS)-induced deficit of fighting behavior. Pol J Pharmacol. 2004;3:305-11.

20. Willner P. The validity of animal models of depression. Psychopharmacology (Berl). 1984;83(1):1-16.

21. Wu LM, Liu YS, Tong XH, Shen N, Jin RT, Han H, et al. Inhibition of follicular development induced by chronic unpredictable stress is associated with growth and differentiation factor 9 and gonadotropin in mice. Biol Reprod 2012;86(4):121,1-7.

22. Wu LM, Hu MH, Tong XH, Han H, Shen N, Jin RT, et al. Chronic unpredictable stress decreases expression of Brain-Derived Neurotrophic Factor (BDNF) in mouse ovaries: relationship to oocytes developmental potential. PLoS One. 2012;7:e52331.

23. Ritossa FA. A new puffing pattern induced by a temperature shock and DNP in Drosophila. Experientia. 1962;18:571-3.

24. Neuer A, Spandorfer SD, Giraldo P, Dieterle S, Rosenwaks Z, Witkin SS. The role of heat shock proteins in reproduction. Hum Reprod Update. 2000;6(2):149-59.

25. Bernardini C, Fantinati P, Zannoni A, Forni M, Tamanini C, Bacci ML. Expression of HSP70/HSC70 in swine blastocysts: effects of oxidative and thermal stress. Mol Reprod Dev. 2004;69:303-7.

26. Gamaro GD, Prediger ME, Lopes J, Bassani MG, Dalmaz C. Fluoxetine alters feeding behavior and leptin levels in chronically-stressed rats. Pharmacol Biochem Behav. 2008;90:312-7.

27. Langford-Smith A, Langford-Smith KJ, Jones SA, Wynn RF, Wraith JE, Wilkinson FL, et al. Female mucopolysaccharidosis IIIA mice exhibit hyperactivity and a reduced sense of danger in the open field test. PLoS One. 2011;6(10):e25717.

28. Peter RB. A textbook of In Vitro Fertilization and Assisted Reproduction. 2nd ed. Bourn Hall Clinic, Bourn, Cambridge, U K: The Parthenon Publication Group; 1999. p. 185-201. 
29. Zhu S, Shi R, Wang J, Wang JF, Li XM. Unpredictable chronic mild stress not chronic restraint stress induces depressive behaviours in mice. Neuroreport. 2014;25(14):1151-5.

30. Hirano T, Kobayashi Y, Omotehara T, Tatsumi A, Hashimoto R, Umemura $Y$, et al. Unpredictable chronic stress-induced reproductive suppression associated with the decrease of kisspeptin immunoreactivity in male mice. J Vet Med Sci. 2014;76(9):1201-8.

31. Kirby ED, Geraghty AC, Ubuka T, Bentley GE, Kaufer D. Stress increases putative gonadotropin inhibitory hormone and decreases luteinizing hormone in male rats. Proc Natl Acad Sci. 2009;106(27):11324-9.

32. Abane $R$, Mezger $V$. Roles of heat shock factors in gametogenesis and development. FEBS J. 2010;277:4150-72.

33. Palubinsky AM, Stankowski JN, Kale AC, Codreanu SG, Singer RJ, Liebler DC et al. CHIP is an essential determinant of neuronal mitochondrial stress signaling. Antioxid Redox Signal. 2015;23(6):535-49

\section{Submit your next manuscript to BioMed Central and take full advantage of:}

- Convenient online submission

- Thorough peer review

- No space constraints or color figure charges

- Immediate publication on acceptance

- Inclusion in PubMed, CAS, Scopus and Google Scholar

- Research which is freely available for redistribution 